\title{
Effects of supplemental lighting with different light qualities on growth and secondary metabolite content of Anoectochilus roxburghii
}

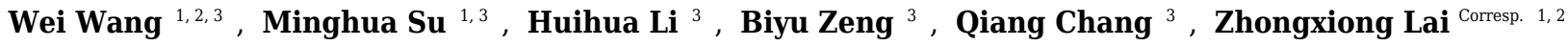 \\ ${ }^{1}$ College of Horticulture, Fujian Agricultural and Forestry University, Fuzhou, Fujian, China \\ 3 Fujian Key Laboratory of Physiology and Biochemistry for Subtropical Plant, Fujian Institute of Subtropical Botany, Xiamen, Fujian, China \\ Corresponding Author: Zhongxiong Lai \\ Email address: Laizx01@163.com
}

Background. Anoectochilus roxburghii is a widespread herbaceous plant with high medicinal value. Wild A. roxburghii resources face extinction due to their slow growth rate and over exploitation. The growing market demand has led to advances in the field of artificial planting of $A$. roxburghii. Methods to increase the economic benefits of cultivation and the production of medicinal ingredients are very useful.

Methods. A. roxburghii was exposed to red light (RL), blue light (BL), yellow light (YL), green light (GL) or white light (WL) as supplemental lighting at night (18:00-02:00) in a greenhouse or were left in darkness (control, CK), to investigate the effects of various light qualities on growth indices, photosynthetic pigments, chlorophyll fluorescence, root vitality, stomatal density, soluble proteins, sugars and the accumulation of secondary metabolites.

Results. Supplementation of BL had a positive effect on $A$. roxburghii growth and secondary metabolite accumulation. Leaf number, stem diameter, fresh weight, dry weight, chlorophyll a content, and secondary metabolite (total flavonoids, total polyphenols) content increased significantly. YL treatment showed significantly higher soluble sugar and polysaccharide contents than the control.

Discussion. BL treatment was conducive to promoting the growth and accumulation of secondary metabolites (total flavonoids, total polyphenols); YL treatment significantly increased the content of soluble sugar and polysaccharides than the control. Polysaccharides and total flavonoids are the important medicinal ingredient of Anoectochilus, so future research will focus on the combination of blue and yellow light. 
1

6

\section{Effects of supplemental lighting with different light qualities on growth and secondary metabolite content of Anoectochilus roxburghii}

Wei Wang ${ }^{1,2,3}$, Minghua $\mathrm{Su}^{1,3^{*}}$, Huihua $\mathrm{Li}^{3}$, Biyu Zeng ${ }^{3}$, Qiang Chang ${ }^{3}$ and Zhongxiong Lai ${ }^{1,2^{*}}$

${ }^{1}$ College of Horticulture, Fujian Agricultural and Forestry University, Fuzhou, Fujian 350002, China

${ }^{2}$ Institute of Horticultural Biotechnology, Fujian Agricultural and Forestry University, Fuzhou, Fujian 350002, China;

${ }^{3}$ Fujian Key Laboratory of Physiology and Biochemistry for Subtropical Plant, Fujian Institute of Subtropical Botany, Xiamen, Fujian 361006, China

Corresponding Author 1:

Zhongxiong Lai

No.15 Shangxiadian Road, Cangshan District, Fuzhou City, Fujian Province, 350002, China

Email: Laizx01@163.com

Corresponding Author 2:

Minghua Su

No.800 Jiahe Road, Huli District, Xiamen City, Fujian Province, 361006, China

Email:mhsu068@163.com 


\section{ABSTRACT}

34 Background. Anoectochilus roxburghii is a widespread herbaceous plant with high medicinal value. Wild $A$. roxburghii resources face extinction due to their slow growth rate and over exploitation. The growing market demand has led to advances in the field of artificial planting of A. roxburghii. Methods to increase the economic benefits of cultivation and the production of medicinal ingredients are very useful.

Methods. A. roxburghii was exposed to red light (RL), blue light (BL), yellow light (YL), green light (GL) or white light (WL) as supplemental lighting at night (18: 00-02: 00) in a greenhouse or were left in darkness (control, CK), to investigate the effects of various light qualities on growth indices, photosynthetic pigments, chlorophyll fluorescence, root vitality, stomatal density, soluble proteins, sugars and the accumulation of secondary metabolites.

Results. Supplementation of BL had a positive effect on A. roxburghii growth and secondary metabolite accumulation. Leaf number, stem diameter, fresh weight, dry weight, chlorophyll a content, and secondary metabolite (total flavonoids, total polyphenols) content increased significantly. YL treatment showed significantly higher soluble sugar and polysaccharide contents than the control.

Discussion. BL treatment was conducive to promoting the growth and accumulation of secondary metabolites (total flavonoids, total polyphenols); YL treatment significantly increased the content of soluble sugar and polysaccharides than the control. Polysaccharides and total flavonoids are the important medicinal ingredient of Anoectochilus, so future research will focus on the combination of blue and yellow light. 
Anoectochilus roxburghii (Orchidaceae) is a valued perennial herb that is used for medicinal and ornamental purposes in China and many Asian countries. The chemical composition of $A$. roxburghii includes flavonoids, polysaccharides, alkaloids, amino acids, trace elements, organic acids, cardiac glycosides, and steroids (Han, Yang \& Jin, 2008). Pharmacological studies have indicated that $A$. roxburghii has unique medicinal properties, including antihyperglycemic (Shih, Wu \& Lin, 2002; Cui et al., 2013; Zhang et al., 2015), hepatoprotective (Zeng et al., 2016; Zeng et al., 2017; Yang et al., 2017), antitumor and immunostimulating effects (Tseng et al., 2006), renal protection ( $\mathrm{Li}$ et al., 2016), vascular protection (Liu et al., 2013), and antioxidant activity (Shao et al., 2014a). Various nutraceutical health products have been produced from $A$. roxburghii because of its healthcare effects. Nevertheless, wild resources of $A$. roxburghii face extinction due to overexploitation, low seed germination rate, slow growth rate, specific growth conditions and increasingly severe environmental problems (Shao et al., 2014b). Artificial cultivation is an effective way to meet the growing market demand for A. roxburghii and to avoid the extinction of the wild resources.

Many studies indicate that light has a positive effect on the growth and accumulation of plant secondary metabolites (Agati et al., 2011; Koyama et al., 2012; Liu et al., 2015). Light intensity is one of the important factors of light conditions. A. roxburghii belongs to the sciophyte family. Shading is necessary for the normal growth of $A$. roxburghii, which has adapted to shade conditions through increased levels of chloroplasts, grana, and grana lamellae, and higher peroxidase (POD) and superoxidase (SOD) activities (Shao et al., 2014). And Anoectochilus is suitable for cultivation under low light intensity a photosynthetic photon flux (PPF) of 30 to 50 $\mu \mathrm{mol} \cdot \mathrm{m}^{-2} \cdot \mathrm{s}^{-1}$ for both growth and the production of secondary metabolites (total flavonoids) ( $\mathrm{Ma}$ et al., 2010). In addition to light intensity, light quality is one of the important factors of light conditions too, the visible light spectrum $(400-700 \mathrm{~nm})$, especially blue $(400-500 \mathrm{~nm})$ and red $(600-700 \mathrm{~nm})$ lights have the greatest impact on plant growth because they are the major energy sources for photosynthetic $\mathrm{CO}_{2}$ assimilation in plants, and as a signal received by photoreceptors it regulates growth, differentiation, and plant secondary metabolism (Wang et al., 2001). In instance, the height of Salvia miltiorrhiza Bunge and Tagetes erecta L.was higher under BL treatment than under RL or fluorescent WL treatments (Heo et al., 2002). Whereas, Manivannan et al. (2015) found that RL had the strongest stimulatory effect on the weight and height of Rehmannia glutinosa (Gaertn.) DC. Maximal total flavonoid content and total phenolic content was observed when Prunella vulgaris was grown under BL (Fazal et al., 2016). However, the highest flavonoids and chlorogenic acid content of Tartary buckwheat sprouts were observed with red + blue and white lights (Seo et al., 2015).

Anoectochilus is sensitive to light, many studies about light intensity of Anoectochilus have been reported, but the effects of LED light quality on the yield and bioactive substance content of A. roxburghii have not been studied. Thus, the hypothesis of this study was that supplemental lighting with different LED light qualities at night has a positive effect on the growth and secondary metabolism of $A$. roxburghii. This study aimed to use energy-saving light-emitting 
104 diode (LED) lamps to explore the effects of supplemental lighting with different light qualities on

105 growth, photosynthetic pigments, chlorophyll fluorescence, root vitality, stomatal density, soluble 106 protein, sugars and accumulation of secondary metabolites in the cultivation stage of $A$. 107 roxburghii and to determine the optimal light quality to increase the medicinal value and 108 economic benefits for Anoectochilus growers.

MATERIALS AND METHODS

110

111

\section{Plant Materials and Growth Conditions}

Test species: Anoectochilus roxburghii cv. Narrow-leaf.

The experiment was performed in December of 2016 in the greenhouse of the Fujian Institute of Subtropical Botany, China (24 $26^{\prime} \mathrm{N}, 118^{\circ}$ 04' E). The day (highest)/night (lowest) temperatures of the greenhouse were $23 / 12^{\circ} \mathrm{C}$. A. roxburghii plantlets were obtained from Diyuan Biotechnology Co., Ltd. (Xiamen, China). Tissue-culture bottles were opened to acclimate the plantlets to the environmental conditions of the greenhouse for $15 \mathrm{~d}$. The average fresh weight of the acclimated plantlets was $0.55 \mathrm{~g}$ and leaf number was 3.8 . These plantlets were transplanted to plastic trays $(50 \times 30 \times 5 \mathrm{~cm})$ at a density of 110 plants per tray. The cultivation soil was composed of peat moss and perlite in a 2:1 ratio by volume.

In the supplemental lighting experiment, natural light was used during the day and LED lamps were used as supplemental lighting at night. LED lamps were provided by Xiamen Guangpu Electronics Co., Ltd. (Xiamen, China). Plantlets were subjected to five different light quality treatments: red light (RL; 580-660 nm, peak wavelength $630 \mathrm{~nm})$, blue light (BL; 440-540 nm, peak wavelength $469 \mathrm{~nm}$ ), yellow light (YL; 540-620 nm, peak wavelength $592 \mathrm{~nm}$ ), green light (GL; 460-600 nm, peak wavelength $519 \mathrm{~nm}$ ), white light (WL; 420-780 nm) and a control without supplemental lighting (CK). The spectral characteristics of the lamps are shown in Fig. 1, as measured by a MK350S spectrometer (United Power Research Technology Corporration, Taiwan). Each treatment consisted of one tray with three replications (3x110 plants for each treatment). The photoperiod of supplemental lighting was $8 \mathrm{~h} / \mathrm{d}$ (18: 00-02: 00). A. roxburghii grown under different light qualities at night are shown in Fig. 2.

The LED lamps were placed above of the plantlets. The conclusion from Ma et al. (2010) was referenced and the height of each light fixture was adjusted to ensure the light intensity was $30 \pm 1$ $\mu \mathrm{mol} \cdot \mathrm{m}^{-2} \cdot \mathrm{s}^{-1}$ (light intensity was measured with a LI-250A light meter (LI-COR Biosciences, Lincoln, Nebraska, USA)). Different treatments were insulated from one another by black shading materials.

\section{Determination of the Physiological and Biochemical Indexes}

After $40 \mathrm{~d}$ of treatment, 40 plantlets were chosen randomly from each repeat for subsequent testing. Nine of these 40 plantlets were selected randomly for biomass analysis within each treatment. And six of these 40 plantlets were selected randomly for root activity analysis and stomata observation within each treatment. The others were stored in a $-80^{\circ} \mathrm{C}$ refrigerator after flash freezing.

\section{Growth and Biomass Parameter Analysis}


145 The leaf numbers, length and width of each leaf, stem diameter, stem length, root length, root 146 numbers, fresh weight and dry weight were separately determined. The fresh weights of the 147 plantlets were measured with an electronic balance (Sartorius, Hamburg, Germany), and the 148 plantlets were dried to a constant weight at $80^{\circ} \mathrm{C}$ to determine their dry weights. The stem 149 diameter was measured with a vernier caliper (Tricle Brand Tools, Shanghai, China). The stem 150 length was measured from the top of the plantlet to the base of the first root. The root length was 151 152

\section{Chlorophyll Content}

Chlorophyll content was determined following the method from Yuan et al. (2010). Fresh mature leaves (Half-gram) were collected from each treatment for the determination of chlorophyll content (Chl a, Chl b, Chl a+b,). Samples were ground in a mortar. Chlorophylls were extracted in $15 \mathrm{ml}$ acetone-water solvent $(80 \%$, v/v) (Xilong Scientific Co., Ltd., Shantou, China) in the dark at room temperature. Chlorophyll quantification was measured at 665 and $649 \mathrm{~nm}$. The results are expressed as milligrams of chlorophyll mass per gram of fresh weight.

\section{Chlorophyll Fluorescence}

Chlorophyll fluorescence was measured with a MINIPAM fluorometer (Walz, Effeltrich, Germany) (Schreiber et al., 1997). Leaves with consistent maturity were light adapted for approximately 15 min prior to measurements of the effective quantum yield of photochemical energy conversion (Yield) and photochemical (qP) and nonphotochemical (qN) quenching of chlorophyll fluorescence. The effective quantum yield of photochemical energy conversion at steady-state photosynthesis was calculated as Yield $=(\mathrm{Fm} '-\mathrm{Fs}) / \mathrm{Fm}$ ', $\mathrm{qP}$ was calculated as $(\mathrm{Fm}-$ $\left.\mathrm{Fm}^{\prime}\right) /\left(\mathrm{Fm}{ }^{\prime}-\mathrm{F}_{0}\right)$, and $\mathrm{qN}$ was calculated as $\left(\mathrm{Fm}^{\prime}-\mathrm{F}_{0}{ }^{\prime}\right) /\left(\mathrm{Fm}-\mathrm{F}_{0}\right)$.

\section{Soluble Sugar, Reducing Sugar and Polysaccharide}

Fresh leaves $(0.2 \mathrm{~g})$ were homogenized in liquid nitrogen and soluble sugar was extracted in boiling ultrapure water $(15 \mathrm{ml})$ for $20 \mathrm{~min}$. Following centrifugation at $15000 \times \mathrm{g}$ for $5 \mathrm{~min}$, the residues were re-extracted under the same conditions. The respective extracts and re-extracts were pooled before analysis. All samples were extracted in duplicate.

The soluble sugar content was evaluated using the anthrone colorimetric method ( $L i, 2000 a)$. The extracts $(0.5 \mathrm{ml})$ were incubated with the anthrone reagent $(5 \mathrm{ml})$ (Shanghai Macklin Biochemical Co., Ltd., Shanghai, China) in a boiling water bath $(10 \mathrm{~min})$ to yield a blue-green color and after cooling, its optical density was measured at $620 \mathrm{~nm}$. Standard solutions of glucose (Xilong Scientific Co., Ltd., Shantou, China) were prepared in ultrapure water at a concentration of $10 \mu \mathrm{g} / \mathrm{ml}$.

The reducing sugar content was evaluated by 3, 5-dinitrosalicylic acid (DNS) colorimetry ( $L i$, $2000 b)$. The extracts $(0.5 \mathrm{ml})$ were incubated with the DNS color solution $(5 \mathrm{ml})$ (Sinopharm Chemical Reagent Co., Ltd., Shanghai, China) in a boiling water bath (5 min) and after cooling, the optical density was measured at $540 \mathrm{~nm}$. Standard solutions of glucose (Sinopharm Chemical Reagent Co., Ltd., Shanghai, China) were prepared in ultrapure water at a concentration of 1 $\mathrm{mg} / \mathrm{ml}$.

Polysaccharide content=soluble sugar content-reducing sugar content. 
188

189

190

191

192

193

194

195

196

197

198

199

200

201

202

\section{Stomata Observations}

Pretreatment of samples was performed based on the method of Li, Tang \& Xu (2013). Fully expanded leaves were chosen from each plantlet to observe the stomata. The abaxial and adaxial surfaces of the leaves were wiped with wet absorbent cotton fiber. Then, transparent nail polish was smeared on the two sides of the leaves. After the nail polish had air-dried and formed a membrane, transparent adhesive tape was pressed onto each leaf and was subsequently stripped off. The transparent adhesive tape was then pressed on a slide, which was treated with a neutral plastic seal and made into a temporary slide. The slides were imaged using a Leica DMI 3000B microscope (Leica Microsystems, Wetzlar, Germany). The length, width and density of stomata were measured with Leica LAS Image Analysis software (Leica Microsystems, Wetzlar, Germany). Stomatal area $=$ length $\times$ width $\times 3.14 \times 1 / 4\left(\mu \mathrm{m}^{2}\right)$. Stomatal density $=$ number $/$ field $/$ field area.

\section{Root Activity}

Root activity was determined using the triphenyltetrazolium chloride method $(\mathrm{Li}, 2000 \mathrm{c})$. A total of $0.3 \mathrm{~g}$ samples of fresh roots were treated with $5 \mathrm{ml}$ of $0.01 \mathrm{M} \mathrm{2,3,5-triphenyltetrazolium}$ chloride (TTC) (Sinopharm Chemical Reagent Co., Ltd., Shanghai, China) and $5 \mathrm{ml}$ of $0.07 \mathrm{M}$ potassium phosphate buffer (PBS) (Sinopharm Chemical Reagent Co., Ltd., Shanghai, China) for $2 \mathrm{~h}$ at $37^{\circ} \mathrm{C}$. The reaction was terminated with $2 \mathrm{ml}$ of $1 \mathrm{M}$ sulfuric acid (Xilong Scientific Co., Ltd., Shantou, China), and the roots were removed and rinsed two to three times with distilled water. The samples were subsequently placed in a mortar with quartz sand $(0.3 \mathrm{~g})$ with $10 \mathrm{ml}$ of acetone (Xilong Scientific Co., Ltd., Shantou, China) and ground until the root turned white. The optical density was then measured at $485 \mathrm{~nm}$. To make a standard curve, $0.25,0.50,1.00,1.50$, or $2.00 \mathrm{ml}$ of $0.01 \mathrm{M}$ TTC was added to 5 volumetric flasks, and sodium thiosulfate (Xilong Scientific Co., Ltd., Shantou, China) and distilled water were added to reach a volume of $10 \mathrm{ml}$.

\section{Soluble Protein}

The soluble protein content was measured following the method of Bradford (1976). A total of 0. $2 \mathrm{~g}$ of fresh leaf samples were ground in a mortar with liquid nitrogen to which $5 \mathrm{ml}$ of $0.07 \mathrm{M}$ potassium phosphate buffer (PBS) (Sinopharm Chemical Reagent Co., Ltd., Shanghai, China) was added, followed by centrifugation at $5000 \times \mathrm{g}$ for $10 \mathrm{~min}$. The supernatant was saved and then $1 \mathrm{ml}$ of extract and $5 \mathrm{ml}$ of coomassie brilliant blue G-250 (Sinopharm Chemical Reagent Co., Ltd., Shanghai, China) were thoroughly mixed. To generate a standard curve, 0, 0. 2, 0. 4, 0. 6, 0. 8 , or $1 \mathrm{ml}$ of $100 \mathrm{~g} / \mathrm{l}$ of bovine serum albumin (Sinopharm Chemical Reagent Co., Ltd., Shanghai, China) was added to 6 volumetric flasks, and distilled water was added to reach a total volume of $1 \mathrm{ml}$. The optical density was measured at $595 \mathrm{~nm}$.

\section{Total Flavonoids}

For total flavonoids estimation, the method of Marinova, Ribarova \& Atanassova (2005) was followed with slight modification. Half-gram samples of fresh leaves were homogenized in liquid nitrogen and total flavonoids were extracted in $10 \mathrm{ml}$ of ethanol-water solvent $(60 \%$, v/v) (Xilong Scientific Co., Ltd., Shantou, China) in the dark (3 h) and then centrifuged at 15,000 rpm for 10 
231

232

233

234

235

236

237

238

239

240

241

242

243

min. The supernatant $(1 \mathrm{ml})$ was mixed with a $0.73 \mathrm{M}$ sodium nitrite solution $(0.4 \mathrm{ml})$ (Xilong Scientific Co., Ltd., Shantou, China), a 0. $47 \mathrm{M}$ aluminum nitrate solution (0.4 ml) (Xilong Scientific Co., Ltd., Shantou, China), 1 M sodium hydroxide (4 ml) (Guangdong Guanghua SciTech Scientific Co., Ltd., Guangzhou, China) and ethanol-water solvent (60\%, v/v) (0. $2 \mathrm{ml})$. The mixture was shaken for $12 \mathrm{~min}$, then its optical density was measured at $510 \mathrm{~nm}$. The total flavonoid content was calculated as milligrams of rutin (Shanghai Macklin Biochemical Co., Ltd., Shanghai, China) equivalent per gram of fresh weight.

\section{Total Polyphenols}

The total polyphenol content was determined with the Folin-Ciocalteu reagent according to the method of Zuo et al. (2012). For polyphenol estimation, half-gram samples of fresh leaves were homogenized in liquid nitrogen and total polyphenols were extracted in $15 \mathrm{ml}$ of distilled water (20 $\mathrm{min})$ and then centrifuged at 15,000 rpm for $15 \mathrm{~min}$. The supernatant $(1 \mathrm{ml})$ was mixed with Folin-Ciocalteau reagent (1.5 ml) (Sinopharm Chemical Reagent Co., Ltd., Shanghai, China) and 0. $94 \mathrm{M}$ sodium carbonate $(4 \mathrm{ml}$ ) (Xilong Scientific Co., Ltd., Shantou, China). The mixture was incubated in the dark for $2 \mathrm{~h}$ at room temperature. Its optical density was then measured at 765 $\mathrm{nm}$, and the total polyphenol content was calculated as milligrams of gallic acid (Shanghai Macklin Biochemical Co., Ltd., Shanghai, China) equivalent per gram of fresh weight.

\section{Statistical Analysis}

SPSS Version 13. 0 (SPSS Inc., Chicago, IL, USA) was used for all statistical analysis. Data was analyzed by one factor, light quality. The results were analyzed by one-way analysis of variance (ANOVA). Duncan's multiple range test was employed to detect differences between means (with $P$ set to 0.05 ).

\section{RESULTS}

\section{Morphological Observations}

The growth indices of $A$. roxburghii treated with different light qualities on Day 40 are summarized in Fig. 3 and Table 1; overall, the BL treatment made $A$. roxburghii plantlets grow robustly. Significantly higher leaf numbers $(5.00 \pm 0.50$ vs $5.89 \pm 0.60, P<0.05)$ were observed under the BL treatment, at $17.8 \%$ higher than the control. However, the leaf numbers did not

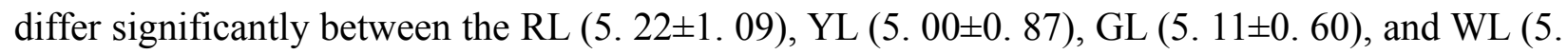
$33 \pm 0$. 71) treatments and the control. The leaf length, leaf width, stem length and root numbers did not differ significantly between all supplemental lighting treatments and the control. Stem diameter was significantly greater in the BL treatment $(2.38 \pm 0.13$ vs $2.68 \pm 0.43 \mathrm{~mm}, P$ \& 0 .

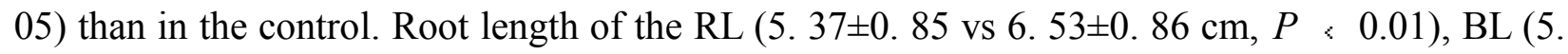
$37 \pm 0.85$ vs $6.43 \pm 1.09 \mathrm{~cm}, P<0.05)$ and $\mathrm{YL}(5.37 \pm 0.85$ vs $6.76 \pm 0.56 \mathrm{~cm}, P<0.01)$ treatments was significantly higher than in the control. Fresh weight (1. $35 \pm 0.09$ vs $1.58 \pm 0.12$ $\mathrm{g}, P<0.01)$ and dry weight $(0.15 \pm 0.02$ vs $0.20 \pm 0.03 \mathrm{~g}, P<0.01)$ of the BL treatment were significantly greater than in the control. However, the RL, YL, GL and WL treatments had no significant effect on the yield of $A$. roxburghii. 


\section{Photosynthetic Pigment Contents}

274

As shown in Fig. 4, a significantly higher chlorophyll a content $(0.59 \pm 0.03 \mathrm{vs} 0.82 \pm 0.07 \mathrm{mg} / \mathrm{g}$ FW, $P$ < 0.05$)$ was observed with the BL treatment, at $38.98 \%$ higher than in the Control. In this study, chlorophyll b content was not affected significantly by different light qualities. The chlorophyll $\mathrm{a}+\mathrm{b}$ content showed a similar trend compared to chlorophyll a. However, different light qualities had no significant effect on the chlorophyll $\mathrm{a}+\mathrm{b}$ content of $A$. roxburghii. The highest chlorophyll $\mathrm{a}+\mathrm{b}$ content $(1.19 \pm 0.11 \mathrm{mg} / \mathrm{g}$ FW) was observed with the BL treatment, at 22. $6 \%$ higher than in the control $(0.97 \pm 0.03 \mathrm{mg} / \mathrm{g} \mathrm{FW})$, but this increase was not statistically significant $(P, 0.05)$.

\section{Chlorophyll Fluorescence}

Different light qualities had variable effects on the chlorophyll fluorescence of $A$. roxburghii (Fig. 5). The YL treatment resulted in a significant increase in yield $(0.47 \pm 0.12$ vs $0.62 \pm 0.08, P$; $0.05)$, at $31.9 \%$ higher than in the control. A significant decrease in yield was observed in RL ( 0 . $47 \pm 0.12$ vs $0.32 \pm 0.06, P<0.05)$ treatment, at $31.9 \%$ lower than in the control. However, the

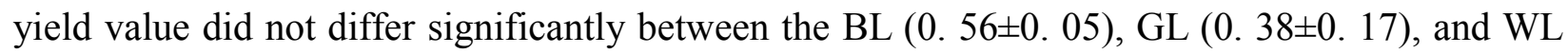
(0. 34 \pm 0.11$)$ treatments and the control.

There was no significant difference in the $\mathrm{qP}$ value between all of the supplemental lighting treatments and the control.

The qN value was significantly higher in the RL treatment $(0.44 \pm 0.22$ vs $0.69 \pm 0.23, P$ \& 0 . 05), GL treatment (0.44 \pm 0.22 vs $0.68 \pm 0.13, P<0.05)$, and WL treatment $(0.44 \pm 0.22$ vs 0 . $82 \pm 0.18, P<0.01)$ than in the control. However, the $\mathrm{qN}$ value did not differ significantly between the $\operatorname{BL}(0.55 \pm 0.20)$, and YL $(0.32 \pm 0.06)$ treatments and the control.

\section{Soluble Sugar, Reducing Sugar and Polysaccharide Contents}

The soluble sugar content was significantly higher in the YL treatment (27. 10 \pm 4 . 21 vs 32. $51 \pm 3$. $32 \mathrm{mg} / \mathrm{g} \mathrm{FW}, P<0.05)$ than in the control. A significantly lower soluble sugar content was observed in the WL treatment $(27.10 \pm 4.21 \mathrm{vs} 20.53 \pm 1.95 \mathrm{mg} / \mathrm{g} \mathrm{FW}, P<0.01)$ than in the Control. The soluble sugar content did not differ significantly between the RL (30.52 $\pm 2.03 \mathrm{mg} / \mathrm{g}$ FW), BL (27. $38 \pm 1.45 \mathrm{mg} / \mathrm{g} \mathrm{FW})$, and GL (28. $1 \pm 1.32 \mathrm{mg} / \mathrm{g} \mathrm{FW)} \mathrm{and} \mathrm{control} \mathrm{treatments} \mathrm{(27.}$ $10 \pm 4.21 \mathrm{mg} / \mathrm{g} \mathrm{FW}$ ) (Fig. 6).

The reducing sugar content did not differ significantly between the RL (5.62 $\pm 0.26 \mathrm{mg} / \mathrm{g} \mathrm{FW}$ ),

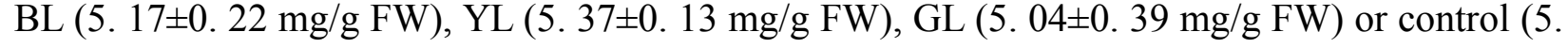
$54 \pm 0.38 \mathrm{mg} / \mathrm{g} \mathrm{FW})$ treatments, but a significantly lower reducing sugar content was observed in the WL treatment (5.54 0.38 vs $4.14 \pm 0.22 \mathrm{mg} / \mathrm{g} \mathrm{FW}, P<0.01)$ (Fig. 6).

The polysaccharide content was significantly higher in the YL treatment $(21.55 \pm 4.58$ vs 27. $13 \pm 3.19 \mathrm{mg} / \mathrm{g} \mathrm{FW}, P<0.05)$, at $25.9 \%$ higher than in the control treatments. A significantly

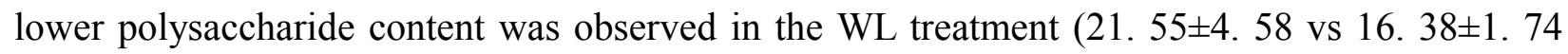
$\mathrm{mg} / \mathrm{g} \mathrm{FW}, P<0.05)$. However, the polysaccharide content did not differ significantly between the RL (24. $90 \pm 1.80 \mathrm{mg} / \mathrm{g} \mathrm{FW}), \mathrm{BL}(22.21 \pm 1.29 \mathrm{mg} / \mathrm{g} \mathrm{FW}), \mathrm{GL}(23.06 \pm 1.18 \mathrm{mg} / \mathrm{g} \mathrm{FW})$ and control (21. $55 \pm 4.58 \mathrm{mg} / \mathrm{g} \mathrm{FW}$ ) treatments (Fig. 6). 
315 Stomatal Observation

316 The stomatal area of $A$. roxburghii grown under different light qualities is shown in Fig. 7

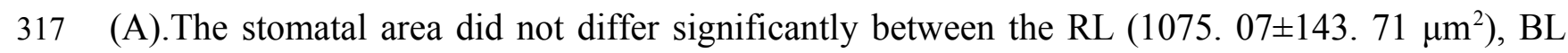

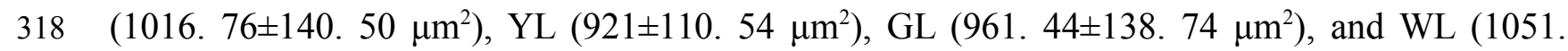
$\left.31958 \pm 69.33 \mu^{2}\right)$ treatments and the control $\left(1003.55 \pm 99.48 \mu \mathrm{m}^{2}\right)$.

As shown in Fig. 7 (B), a significantly higher stomatal density value was observed in the YL treatment $\left(17.9 \pm 2.64\right.$ vs $23.3 \pm 3.78 \mathrm{~mm}^{-2}, P$ < 0.01$)$ than in the Control. However, the stomatal $\left(20 \pm 3.83 \mathrm{~mm}^{-2}\right)$, WL $\left(17.3 \pm 2.42 \mathrm{~mm}^{-2}\right)$ treatments and the control $\left(17.9 \pm 2.64 \mathrm{~mm}^{-2}\right)$.

\section{Root Vitality}

The root vitality was significantly higher in the YL treatment $(0.41 \pm 0.10$ vs $0.53 \pm 0.06 \mathrm{mg} / \mathrm{g} \cdot \mathrm{h}$, $P<0.05)$ than in the control. However, the root vitality did not differ significantly between the RL (0.33 $\pm 0.08 \mathrm{mg} / \mathrm{g} \cdot \mathrm{h}), \mathrm{BL}(0.35 \pm 0.01 \mathrm{mg} / \mathrm{g} \cdot \mathrm{h}), \mathrm{GL}(0.46 \pm 0.02 \mathrm{mg} / \mathrm{g} \cdot \mathrm{h})$, and WL $(0.41 \pm 0.02$ $\mathrm{mg} / \mathrm{g} \cdot \mathrm{h})$ treatments and the control $(0.41 \pm 0.10 \mathrm{mg} / \mathrm{g} \cdot \mathrm{h})($ Fig. $7 \mathrm{C})$.

\section{Soluble Protein Content}

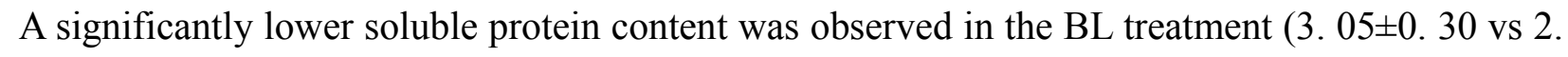
$30 \pm 0.28 \mathrm{mg} / \mathrm{g} \mathrm{FW}, P$ < 0.01$)$ than in the control. However, soluble protein content did not differ significantly between the RL (2. $83 \pm 0.32 \mathrm{mg} / \mathrm{g} \mathrm{FW})$, YL (2. $63 \pm 0.09 \mathrm{mg} / \mathrm{g} \mathrm{FW}), \mathrm{GL}(3.13 \pm 0$. $36 \mathrm{mg} / \mathrm{g} \mathrm{FW})$, and WL (2. $72 \pm 0.17 \mathrm{mg} / \mathrm{g} \mathrm{FW})$ treatments and the control( $3.05 \pm 0.30 \mathrm{mg} / \mathrm{g} \mathrm{FW})$ (Fig. 7 D).

\section{Secondary Metabolite Contents}

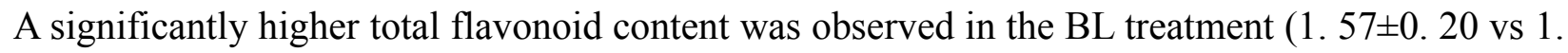
$95 \pm 0.03 \mathrm{mg} / \mathrm{g} \mathrm{FW}, P<0.01$ ), at $24.2 \%$ higher than in the control treatment (Fig. $7 \mathrm{E}$ ). The total flavonoid content did not differ significantly between the RL (1. 74 $\pm 0.11 \mathrm{mg} / \mathrm{g} \mathrm{FW})$, YL (1. $59 \pm 0.08 \mathrm{mg} / \mathrm{g} \mathrm{FW}), \mathrm{GL}(1.72 \pm 0.02 \mathrm{mg} / \mathrm{g} \mathrm{FW}), \mathrm{WL}(1.56 \pm 0.14 \mathrm{mg} / \mathrm{g} \mathrm{FW})$ and control (1. $57 \pm 0.20 \mathrm{mg} / \mathrm{g} \mathrm{FW})$ treatments.

The total polyphenol content was significantly higher in the BL treatment (3. 70 \pm 0.12 vs 4 . $77 \pm 0.23 \mathrm{mg} / \mathrm{g} \mathrm{FW}, P$ < 0.01$)$ than in control treatment. A significantly lower total polyphenol content was observed in the GL treatment $(3.70 \pm 0.12$ vs $3.30 \pm 0.54 \mathrm{mg} / \mathrm{g} \mathrm{FW}, P$ < 0.05$)$ than in the control. The total polyphenol content did not differ significantly between the RL (4. $38 \pm 0$. $43 \mathrm{mg} / \mathrm{g} \mathrm{FW}), \mathrm{YL}(3.52 \pm 0.04 \mathrm{mg} / \mathrm{g} \mathrm{FW}), \mathrm{WL}(4.12 \pm 0.71 \mathrm{mg} / \mathrm{g} \mathrm{FW})$ and control (3. $70 \pm 0.12$ $\mathrm{mg} / \mathrm{g} \mathrm{FW}$ ) treatment (Fig. $7 \mathrm{~F}$ ).

\section{DISCUSSION}

Light quality is an important environmental factor, amongst the light spectra, red and blue wavelengths are the primary spectral wavelengths and highly influence the plant primary and secondary metabolism (Johkan et al., 2010). Red light is reported to contribute to photosynthetic apparatus development and may increase starch accumulation in several plant species (Kobayashi 
356

357

358

359

360

361

362

363

364

365

366

367

368

369

370

371

372

373

374

375

376

377

378

379

380

381

382

383

384

385

386

387

388

389

390

391

392

393

394

395

396

397

398

et al., 2013). Blue light is important for photosynthesis, chloroplast development, chlorophyll formation, and chemical composition of plants (Hogewoning et al., 2010).

\section{Biomass Parameter Response of $\boldsymbol{A}$. roxburghii to Light Quality}

Biomass is an important indicator in medicinal plants. In the present study, the biomass parameters of $A$. roxburghii differed in their responses to different light qualities, but the BL treatment made $A$. roxburghii plantlets grow robustly. Exposure to the BL treatment significantly increased the leaf numbers, stem diameter, fresh weight and dry weight of $A$. roxburghii. The root length of the RL, BL and YL treatments was significantly higher than in the control. There were similar conclusions in other related studies involving, Stevia rebaudiana Bertoni (Simlat et al., 2016), Cardamine fauriei (Abe et al., 2015), and Rehmannia glutinosa (Manivannan et al., 2015), where exposure to the BL treatment showed the largest leaf numbers. BL is more effective in enhancing fresh weight and dry matter production in buckwheat sprouts (Lee et al., 2014). However, RL had a stimulating effect on leaf numbers and the root length of cucumber seedlings (Su et al., 2014). These results indicate that plant species differ in their responses to light quality, but BL generally promotes plant growth and dry matter accumulation.

\section{Photosynthetic Pigment Response of $A$. roxburghii to Light Quality}

Chlorophyll content is an important determinant of photosynthetic and dry matter production (Ghosh et al., 2004). Studies have confirmed that light, especially BL, plays an important role in the synthesis of plant chlorophyll. Cultured Phalaenopsis 'Fortune Saltzman' seedlings treated with BL for 5 months showed significantly higher responses in terms of chlorophyll a, chlorophyll b and total chlorophyll (Anuchai \& Hsieh, 2017). BL contributes positively to chlorophyll synthesis in Stevia rebaudiana Bertoni, and plantlets grown under RL showed the lowest levels of chlorophyll (Simlat et al., 2016). Senger (1982) documented that BL plays an important role in chloroplast development and the formation of chlorophyll. In our study, BL increased the chlorophyll a content of $A$. roxburghii significantly, Chlorophyll b was not sensitive to light quality. Studies confirm that chlorophyll, especially chlorophyll a, plays an important role in the process of photosynthesis and the accumulation of dry matter (Naidu et al., 1984). In our study, the highest dry matter content of $A$. roxburghii was observed in the BL treatment, which illustrates that BL promoted the synthesis of chlorophyll, especially chlorophyll a, thereby promoting photosynthesis and the accumulation of dry matter.

\section{Chlorophyll Fluorescence Response of $\boldsymbol{A}$. roxburghii to Light Quality}

Chlorophyll fluorescence is an important signal of photosynthetic synthesis and plant responses to the external environment. In our study, the highest yield and lowest qN were observed with the YL treatment, which indicats that YL can improve the photosynthetic efficiency of $A$. roxburghii. The second-highest dry matter content also confirmed the promotion of YL on photosynthetic synthesis in A. roxburghii. There was no significant difference in qP between all treatments and the control. However, different results appear in other similar studies. In $C$. acuminate seedlings, RL increased the efficiency of photosynthesis, while BL caused photoinhibition ( $Y u$ et al., 2016). Wang et al. (2009) found that YL caused a decrease in the quantum yield of the PSII electron transport compared to Cucumis sativus plants grown under WL. These results indicate that plant species differ in their responses to light quality in terms of chlorophyll fluorescence.

\section{Sugar Response of $A$. roxburghii to Light Quality}


As sugars are an important carbon source and osmoregulator of plant growth, sugars levels reflect the photosynthetic capacity of a plant. Light quality is also an important factor affecting the metabolism of sugars in plants. In our study, YL significantly increased the soluble sugar and polysaccharide content of $A$. roxburghii. WL caused a marked decrease in soluble sugars, reducing sugar and polysaccharides in $A$. roxburghii. The significant increase in carbohydrates under the YL treatment also corresponded to the change in chlorophyll fluorescence, which indicates that YL indeed promoted photosynthesis in A. roxburghii. However, the responses to light quality of plants varied among species and cultivars. Anuchai \& Hsieh (2017) showed that RL promoted sugar accumulation significantly in cultured Phalaenopsis seedlings. BL significantly increased the soluble sugar content in Tobacco (Yang et al., 2016). The total sugar from grape skin was highest in blue LED-treated plants, followed by red LED-treated plants (Kondo et al., 2014). The above results indicate that the mechanism of different light qualities regulating the metabolism of carbohydrate in plants is complex and needs further exploration.

\section{Stomata Response of $\boldsymbol{A}$. roxburghii to Light Quality}

Stomata are the pathway for air and water vapor during carbon assimilation, respiration and transpiration, and their quantity is regulated by the opening and closing of guard cells. Many exogenous factors influence the opening and closing of stomata, such as light, temperature and $\mathrm{CO}_{2}$. In our study, YL caused a significant increase in stomatal density in A. roxburghii, but there was no significant difference in the stomatal area between LED light treated plants and control treated plants. In other similar studies, the stomata of different plants responded differently to light quality. In Stevia rebaudiana, BL not only increased the number of stomata but also caused stomatal opening (Simlat et al., 2016). Macedo et al. (2011) found that red and blue fluorescent light reduced the number of stomata on the adaxial face and abaxial face of Alternanthera brasiliana leaves, respectively. These results indicate that the effects of different light qualities on the stomata of different plants are inconsistent, and the mechanism of light regulating plant stomata needs further research.

\section{Soluble Protein Response of $\boldsymbol{A}$. roxburghii to Light Quality}

Soluble protein is an important osmotic regulator and nutrient involved in various metabolic enzymes. Soluble protein content is an embodiment of plant resistance and metabolism. In this study, BL caused a significant decrease in soluble protein levels in $A$. roxburghii, but the soluble protein content did not differ significantly between other treatments and controls. However, the effects of light quality on the soluble protein content in other plants were different. In Prunella vulgaris $\mathrm{L}$, the soluble protein content was higher under white fluorescent tube lights compared to all colored lights (Fazal et al., 2016). The highest total protein content of A. absinthium grown under various colored illuminations was observed under RL (Tariq, Ali \& Abbasi, 2014).

\section{Secondary Metabolite Response of $\boldsymbol{A}$. roxburghii to Light Quality}

Secondary metabolism is an indispensable part of plant life and related closely to plant growth and environmental factors. Light is an essential environmental factor that affects the accumulation of secondary metabolites. BL, UV-B, and UV-A were considered to trigger the gene expression of chalcone synthase (CHS), the first committed step in the flavonoid metabolic pathway, and effect flavonoid metabolism in Arabidopsis (Christie \& Jenkins, 1996; Fuglevand et al., 1996). In Prunella vulgaris L, BL was effective for total phenolic and flavonoid content (Fazal et al., 2016). In Tartary buckwheat sprouts, BL induced the accumulation of flavonoids 
442 (Seo et al., 2015). The phenolic levels in Lactuca sativa L. seedlings treated with BL increased 443 significantly (Johkan et al., 2010). Taulavuori et al. (2016) suggested that both BL and RL may 444 be needed to regulate the accumulation of phenolics in basil. In our study, significantly higher 445 total flavonoid and polyphenol contents were observed in BL. These results indicate that BL 446 promotes the accumulation of plant secondary metabolites, which provides an effective method to 447 increase the medicinal component contents of medicinal plants.

\section{CONCLUSION}

450

451

452

453

454

455

456

457

458

459

460

461

462

463

464

465

The supplementation of LED BL had a positive effect on A. roxburghii, which achieved greater biomass and a markedly higher content of chlorophyll and secondary metabolites (total flavonoids and total polyphenols) compared to controls. These results suggest that the supplementation of LED BL is a good choice for $A$. roxburghii growers to increase production and secondary metabolite content. This is conducive to meeting the increasing market demand while avoiding the extinction of wild resources of $A$. roxburghii. Considering the promotion of the soluble sugar and polysaccharide contents after the YL treatment, further research will focus on the combination of blue and yellow light.

\section{ACKNOWLEDGMENTS}

We thank Xiamen Guangpu Electronics Co., Ltd. for providing LED lamps, and Diyuan (Xiamen) Biotechnology Co., Ltd. for providing A. roxburghii plantlets.

\section{REFERENCES}

Abe K, Kido S, Maeda T, Kami D, Matsuura H, Shimura H, Suzuki T. 2015. Glucosinolate profiles in Cardamine fauriei and effect of light quality on glucosinolate concentration. Scientia Horticulturae 189:12-16 DOI: 10.1016/j.scienta.2015.03.028

Agati G, Cerovic ZG, Pinelli P, Tattini M. 2011. Light-induced accumulation of orthodihydroxylated flavonoids as non-destructively monitored by chlorophyll fluorescence excitation techniques. Environmental and Experimental Botany 73:3-9 DOI: 10.1016/j. envexpbot. 2010.10.002

Anuchai J, Hsieh CH. 2017. Effect of change in light quality on physiological transformation of in vitro Phalaenopsis 'Fortune Saltzman' seedlings during the growth period. Horticulture Journal 86(3):395-402 DOI: 10.2503/hortj.MI-151

Bradford MM. 1976. A rapid and sensitive method for the quantitation of microgram quantities of protein utilizing the principle of protein-dye binding. Analytical biochemistry 72:248-254 DOI:10.1006/abio.1976.9999

Christie JM, Jenkins GI. 1996. Distinct UV-B and UV-A/blue light signal transduction pathways induce chalcone synthase gene expression in Arabidopsis cells. Plant Cell 8(9):1555-1567

Cui SC, Yu J, Zhang XH, Cheng MZ, Yang LW, Xu JY. 2013. Antihyperglycemic and antioxidant activity of water extract from Anoectochilus roxburghii in experimental diabetes. Experimental \& Toxicologic Pathology Official Journal of the Gesellschaft Für Toxikologische Pathologie 
480

65(5):485-488 DOI: 10.1016/j.etp.2012.02.003

Fazal H, Abbasi BH, Ahmad N, Ali SS, Akbar F, Kanwal F. 2016. Correlation of different spectral lights with biomass accumulation and production of antioxidant secondary metabolites in callus cultures of medicinally important Prunella vulgaris L. Journal of Photochemistry \& Photobiology B Biology 159:1-7 DOI:10.1016/j.jphotobiol.2016.03.008

Fuglevand G, Jackson JA, Jenkins GI. 1996. UV-B, UV-A and blue light signal transduction pathways interact synergistically to regulate chalcone synthase gene expression in Arabidopsis. Plant Cell 8(12):2347-2357

Ghosh PK, Ramesh P, Bandyopadhyay KK, Tripathi AK, Hati KM, Misra AK, Acharya CL. 2004. Comparative effectiveness of cattle manure, poultry manure, phosphocompost and fertilizer-NPK on three cropping systems in vertisols of semi-arid tropics. I. Crop yields and system performance. Bioresource Technology 95(1):77-83 DOI: 10.1016/j.biortech. 2004.02.011

Han MH, Yang XW, Jin YP. 2008. Novel triterpenoid acyl esters and alkaloids from Anoectochilus roxburghii. Phytochemical Analysis Pca 19(5):438-443 DOI: 10.1002/pca. 1070

Heo J, Lee C, Chakrabarty D, Paek K. 2002. Growth responses of marigold and salvia bedding plants as affected by monochromic or mixture radiation provided by a Light-Emitting Diode (LED). Plant Growth Regulation 38(3):225-230 DOI: 10.1023/A: 1021523832488

Hogewoning SW, Trouwborst G, Maljaars H, Poorter H, van Ieperen W, Harbinson J. 2010. Blue light dose-responses of leaf photosynthesis, morphology, and chemical composition of Cucumis sativus grown under different combinations of red and blue light. Journal of Experimental Botany 61(11):3107-3117 DOI: 10.1093/jxb/erq132

Johkan M, Shoji K, Goto F, Hashida S, Yoshihara T. 2010. Blue light-emitting diode light irradiation of seedlings improves seedling quality and growth after transplanting in red leaf lettuce. Hortscience, 45(12):1809-1814.

Kobayashi K, Amore T, Lazaro M. 2013. Light-Emitting Diodes (LEDs) for miniature hydroponic Lettuce. Optics and Photonics Journal 3(1):74-77 DOI: 10.4236/opj.2013. 31012

Kondo S, Tomiyama H, Rodyoung A, Okawa K, Ohara H, Sugaya S, Terahara N, Hirai N. 2014. Abscisic acid metabolism and anthocyanin synthesis in grape skin are affected by light emitting diode (LED) irradiation at night. Journal of Plant Physiology 171(10):823-829 DOI: 10.1016/j.jplph.2014.01.001

Koyama K, Ikeda H, Poudel PR, Goto-Yamamoto N. 2012. Light quality affects flavonoid biosynthesis in young berries of Cabernet Sauvignon grape. Phytochemistry 78:54-64 DOI: 10.1016/j.phytochem.2012.02.026

Lee SW, Seo JM, Lee MK, Chun JH, Antonisamy P, Arasu MV, Suzuki T, Al-Dhabi NA, Kim SJ. 2014. Influence of different LED lamps on the production of phenolic compounds in common and Tartary buckwheat sprouts. Industrial Crops and Products 54:320-326 DOI: 10.1016/j.indcrop.2014.01.024

Li HM, Tang CM, Xu ZG. 2013. The effects of different light qualities on rapeseed (Brassica napus L.) plantlet growth and morphogenesis in vitro. Scientia Horticulturae 150:117-124 DOI: $10.1016 /$ j.scienta.2012.10.009 
523

524

525

526

527

528

529

530

531

532

533

534

535

536

537

538

539

540

541

542

543

544

545

546

547

548

549

550

551

552

553

554

555

556

557

558

559

560

561

562

563

564

565

Li HS. 2000a. Principles and techniques of plant physiological biochemical experiment. Beijing: Higher Education Press 194-197.

Li HS. 2000b. Principles and techniques of plant physiological biochemical experiment. Beijing: Higher Education Press 197-199.

Li HS. 2000c. Principles and techniques of plant physiological biochemical experiment. Beijing: Higher Education Press 119-120.

Li L, Li YM, Liu ZL, Zhang JG, Liu Q, Yi LT. 2016. The renal protective effects of Anoectochilus roxburghii polysaccharose on diabetic mice induced by high-fat diet and streptozotocin. Journal of Ethnopharmacology 178:58-65 DOI: 10.1016/j.jep.2015.12.002

Liu Y, Song LL, Yu WW, Hu YY, Ma XH, Wu JS, Ying YQ. 2015. Light quality modifies camptothecin production and gene expression of biosynthesis in Camptotheca acuminata Decne seedlings. Industrial Crops and Products 66:137-143 DOI: 10.1016/j.indcrop.2014. 12.046

Liu ZL, Liu Q, Xiao B, Zhou J, Zhang JG, Li Y. 2013. The vascular protective properties of kinsenoside isolated from Anoectochilus roxburghii under high glucose condition. Fitoterapia 86(4):163-170 DOI: 10.1016/j.fitote.2013.03.006

Macedo AF, Leal-Costa MV, Tavares ES, Lage CLS, Esquibel MA. 2011. The effect of light quality on leaf production and development of in vitro-cultured plants of Alternanthera brasiliana Kuntze. Environmental \& Experimental Botany 70(1):43-50 DOI: 10.1016/ j.envexpbot.2010.05.012

Manivannan A, Soundararajan P, Halimah N, Ko CH, Jeong BR. 2015. Blue LED light enhances growth, phytochemical contents, and antioxidant enzyme activities of Rehmannia glutinosa cultured in vitro. Horticulture Environment \& Biotechnology 56(1):105-113 DOI: 10.1007/s13580-015-0114-1

Marinova D, Ribarova F, Atanassova M. 2005. Total phenolics and total flavonoids in Bulgarian fruits and vegetables. Journal of the University of Chemical Technology and Metallurgy 40(3):255-260.

Ma ZQ, Li SS, Zhang MJ, Jiang SH, Xiao YL. 2010. Light intensity affects growth, photosynthetic capability, and total flavonoid accumulation of Anoectochilus plants. Hortscience 45(6):863-867.

Naidu RA, Krishnan M, Ramanujam P, Gnanam A, Nayudu MV. 1984. Studies on peanut green mosaic virus infected peanut (Arachis hypogaea L.) leaves. II. Chlorophyll-protein complexes and polypeptide composition of thylakoid membranes. Physiological Plant Pathology 25:191198.

Schreiber U, Gademann R, Ralph PJ, Larkum AWD. (1997). Assessment of photosynthetic performance of Prochloron in Lissoclinum patella in hospite by chlorophyll fluorescence measurements. Plant \& Cell Physiology 38(8):945-951.

Senger H. 1982. The effect of blue light on plants and microorganisms. Photochemistry \& Photobiology 35(6):911-920.

Seo JM, Arasu MV, Kim YB, Park SU, Kim SJ. 2015. Phenylalanine and LED lights enhance phenolic compound production in Tartary buckwheat sprouts. Food Chemistry 177:204-213 DOI: 10.1016/j.foodchem.2014.12.094

Shao QS, Deng YM, Liu HB, Zhang AL, Huang YQ, Xu GZ, Li MY. 2014a. Essential oils 
566

extraction from Anoectochilus roxburghii, using supercritical carbon dioxide and their antioxidant activity. Industrial Crops \& Products 60(1):104-112 DOI: 10.1016/j.indcrop. 2014.06.009

Shao QS, Wang HZ, Guo HP, Zhou AC, Huang YQ, Sun YL, Li MY. 2014b. Effects of shade treatments on photosynthetic characteristics, chloroplast ultrastructure, and physiology of Anoectochilus roxburghii. Plos One 9(2):1-9 DOI: 10.1371/journal.pone.0085996

Shih CC, Wu YW, Lin WC. 2002. Antihyperglycaemic and anti-oxidant properties of Anoectochilus formosanus in diabetic rats. Clinical and Experimental Pharmacology and Physiology 29:684-688 DOI: 10.1046/j.1440-1681.2002.03717.x

Simlat M, Ślęzak P, Moś M, Warchoł M, Skrzypek E, Ptak A. 2016. The effect of light quality on seed germination, seedling growth and selected biochemical properties of Stevia rebaudiana Bertoni. Scientia Horticulturae 211:295-304 DOI: 10.1016/j.scienta.2016.09. 009

Su NN, Wu Q, Shen ZG, Xia K, Cui J. 2014. Effects of light quality on the chloroplastic ultrastructure and photosynthetic characteristics of cucumber seedlings. Plant Growth Regulation 73(3):227-235 DOI: 10.1007/s10725-013-9883-7

Tariq U, Ali M, Abbasi BH. 2014. Morphogenic and biochemical variations under different spectral lights in callus cultures of Artemisia absinthium L. Journal of Photochemistry \& Photobiology B Biology 130(1):264-271 DOI: 10.1016/j.jphotobiol.2013.11.026

Taulavuori K, Hyöky V, Oksanen J, Taulavuori E, Julkunen-Tiitto R. 2016. Species-specific differences in synthesis of flavonoids and phenolic acids under increasing periods of enhanced blue light. Environmental \& Experimental Botany 121:145-150 DOI: 10.1016/j. envexpbot.2015.04.002

Tseng CC, Shang HF, Wang LF, Su B, Hsu CC, Kao HY, Cheng KT. 2006. Antitumor and immunostimulating effects of Anoectochilus formosanus Hayata. Phytomedicine International Journal of Phytotherapy \& Phytopharmacology 13(5):366-370 DOI: 10. 1016/j.phymed.2004.01.016

Wang H, Gu M, Cui J, Shi K, Zhou Y, Yu J. 2009. Effects of light quality on $\mathrm{CO}_{2}$ assimilation, chlorophyll-fluorescence quenching, expression of Calvin cycle genes and carbohydrate accumulation in Cucumis sativus. Journal of Photochemistry \& Photobiology B Biology 96(1):30-37 DOI: 10.1016/j.jphotobiol.2009.03.010

Wang YC, Zhang HX, Zhao B, Yuan XF. 2001. Improved growth of Artemisia annua L. hairy roots and artemisinin production under red light conditions. Biotechnology Letters 23:19711973 DOI: 10.1023/A:1013786332363

Yang LY, Wang LT, Ma JH, Ma ED, Li JY, Gong M. 2016. Effects of light quality on growth and development, photosynthetic characteristics and content of carbohydrates in tobacco ( Nicotiana tabacum, L.) plants. Photosynthetica 55(3):1-11 DOI: 10.1007/s11099-0160668-x

Yang ZG, Zhang XH, Yang LW, Pan QW, Li J, Wu YF, Chen MZ, Cui SC, Yu J. 2017. Protective effect of Anoectochilus roxburghii polysaccharide against $\mathrm{CCl}_{4}$-induced oxidative liver damage in mice. International Journal of Biological Macromolecules 96:442-450 DOI: 10.1016/j.ijbiomac.2016.12.039

Yuan GF, Sun B, Yuan J, Wang QM. 2010. Effect of 1-methylcyclopropene on shelf life, visual 
609 quality, antioxidant enzymes and health-promoting compounds in broccoli florets. Food $610 \quad$ Chemistry 118(3):774-781 DOI: 10.1016/j.foodchem.2009.05.062

611 Yu WW, Liu Y, Song LL, Jacobs DF, Du XH, Ying YQ, Shao QS, Wu JS. 2016. Effect of 612 differential light quality on morphology, photosynthesis, and antioxidant enzyme activity in 613 Camptotheca acuminata seedlings. Journal of Plant Growth Regulation 36:1-13 DOI: $614 \quad 10.1007 / \mathrm{s} 00344-016-9625-\mathrm{y}$

615 Zeng BY, Su MH, Chen QX, Chang Q, Wang W, Li HH. 2017. Protective effect of a 616 polysaccharide from Anoectochilus roxburghii against carbon tetrachloride-induced acute liver 617 injury in mice. Journal of Ethnopharmacology 200:124-135 DOI: 10.1016/j.jep.

$618 \quad 2017.02 .018$

619 Zeng BY, Su MH, Chen QX, Chang Q, Wang W, Li HH. 2016. Antioxidant and hepatoprotective 620 activities of polysaccharides from Anoectochilus roxburghii. Carbohydrate Polymers 153:391621398 DOI: 10.1016/j.carbpol.2016.07.067

622 Zhang JG, Liu Q, Liu ZL, Li L, Yi LT. 2015. Antihyperglycemic activity of Anoectochilus 623 roxburghii polysaccharose in diabetic mice induced by high-fat dietand streptozotocin. Journal 624 of Ethnopharmacology 164:180-185 DOI: 10.1016/j.jep.2015.01.050

625 Zuo LL, Wang ZY, Fan ZL, Tian SQ, Liu JR. 2012. Evaluation of antioxidant and 626 antiproliferative properties of three Actinidia (Actinidia kolomikta, Actinidia arguta, Actinidia 627 chinensis) extracts in vitro. International Journal of Molecular sciences 13(5):5506-5518 DOI: $628 \quad 10.3390 /$ ijms 13055506 


\section{Table $\mathbf{1}$ (on next page)}

Effects of supplemental lighting with different light qualities on growth indices of $A$. roxburghii.

Values represent mean $\pm \mathrm{SE}$ of nine replicates; and different letters within a row indicate significant differences at $P<0.05$. $F, P$ and $d f$ represent $F$-value, $P$-value and degree of freedom of the ANOVA, respectively. 


\begin{tabular}{|c|c|c|c|c|c|c|}
\hline Treatment & Blue & Yellow & Green & White & Control & $F\left(\mathrm{df}_{\text {effect }}, \mathrm{df}_{\text {error }}\right) ; P$ \\
\hline \multicolumn{7}{|l|}{ Leaf } \\
\hline \multicolumn{7}{|c|}{ 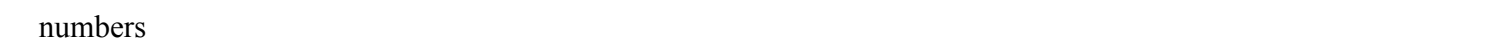 } \\
\hline \multicolumn{7}{|l|}{ Leaf length } \\
\hline$(\mathrm{cm})$ & $3.20 \pm 0.40$ a $3.30 \pm 0.43 \mathrm{a}$ & $3.32 \pm 0.66 \mathrm{a}$ & $3.33 \pm 0.27 \mathrm{a}$ & $3.17 \pm 0.19 \mathrm{a}$ & $3.46 \pm 0.30 \mathrm{a}$ & $F_{(5,48)}=0.590 ; P=0.708$ \\
\hline \multicolumn{7}{|l|}{ Leaf width } \\
\hline$(\mathrm{cm})$ & $2.19 \pm 0.39$ a $2.34 \pm 0.24$ a & $2.26 \pm 0.37 \mathrm{a}$ & $2.26 \pm 0.26 \mathrm{a}$ & $2.12 \pm 0.19 \mathrm{a}$ & $2.39 \pm 0.15 \mathrm{a}$ & $F_{(5,48)}=1.117 ; P=0.364$ \\
\hline $\begin{array}{l}\text { Stem diameter } \\
(\mathrm{mm})\end{array}$ & $2.41 \pm 0.20$ b $\quad 2.68 \pm 0.43 a$ & $2.46 \pm 0.35 \mathrm{ab}$ & $2.31 \pm 0.20 \mathrm{~b}$ & $2.31 \pm 0.15 \mathrm{~b}$ & $2.38 \pm 0.13 b$ & $F_{(5,48)}=2.464 ; P=0.046$ \\
\hline \multicolumn{7}{|l|}{ Stem length } \\
\hline$(\mathrm{cm})$ & $5.89 \pm 0.84$ a $6.53 \pm 1.04 \mathrm{a}$ & $5.97 \pm 0.88 \mathrm{a}$ & $6.01 \pm 0.34 \mathrm{a}$ & $5.83 \pm 0.50 \mathrm{a}$ & $6.01 \pm 0.77 \mathrm{a}$ & $F_{(5,48)}=0.966 ; P=0.448$ \\
\hline \multicolumn{7}{|l|}{ Root } \\
\hline numbers & $4.00 \pm 0.71$ a $4.11 \pm 0.60$ a & $3.44 \pm 0.53 \mathrm{a}$ & $3.44 \pm 0.53 \mathrm{a}$ & $4.11 \pm 0.78 \mathrm{a}$ & $3.44 \pm 0.88 \mathrm{a}$ & $F_{(5,48)}=2.321 ; P=0.057$ \\
\hline \multicolumn{7}{|l|}{ Root length } \\
\hline$(\mathrm{cm})$ & $6.53 \pm 0.86$ a $6.43 \pm 1.09$ a & $6.76 \pm 0.56 \mathrm{a}$ & $6.06 \pm 0.55 \mathrm{ab}$ & $5.99 \pm 1.17 \mathrm{ab}$ & $5.37 \pm 0.85 b$ & $F_{(5,48)}=2.372 ; P=0.053$ \\
\hline \multicolumn{7}{|l|}{ Fresh weight } \\
\hline (g) & $1.43 \pm 0.22 \mathrm{ab} 1.58 \pm 0.12 \mathrm{a}$ & $1.43 \pm 0.24 \mathrm{ab}$ & $1.29 \pm 0.20 \mathrm{~b}$ & $1.41 \pm 0.14 \mathrm{ab}$ & $1.35 \pm 0.09 \mathrm{~b}$ & $F_{(5,48)}=2.683 ; P=0.032$ \\
\hline \multicolumn{7}{|l|}{ Dry weight } \\
\hline (g) & $0.16 \pm 0.03$ b $\quad 0.20 \pm 0.03 \mathrm{a}$ & $0.18 \pm 0.03 \mathrm{ab}$ & $0.15 \pm 0.03 \mathrm{~b}$ & $0.16 \pm 0.02 \mathrm{~b}$ & $0.15 \pm 0.02 \mathrm{~b}$ & $F_{(5,48)}=4.196 ; P=0.003$ \\
\hline
\end{tabular}

\section{1} 2 
Figure 1

Light spectra of supplemental lighting with various light qualities (A: red light; B: blue light; C: yellow light; D: green light; E: white light). 


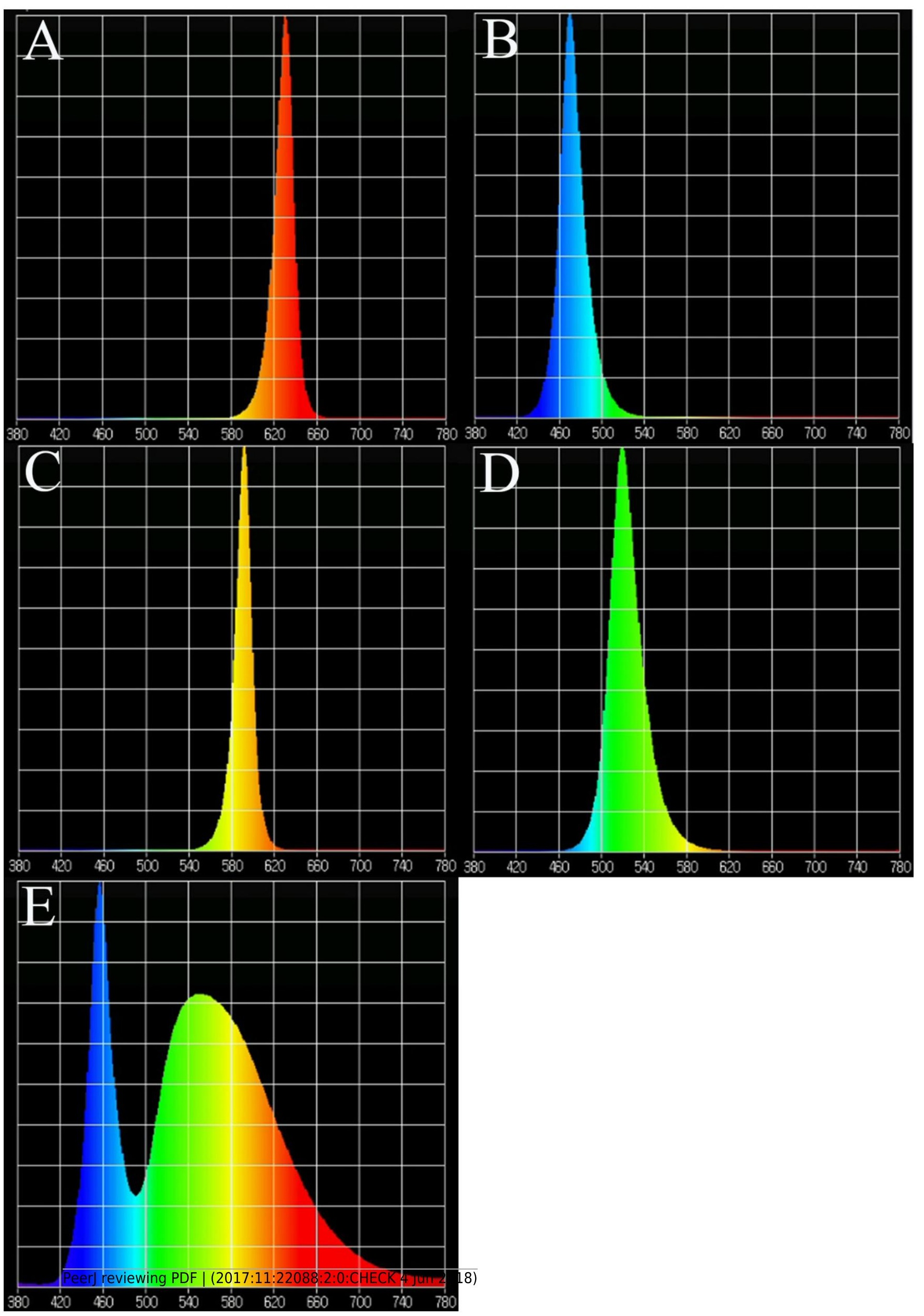


Figure 2

Cultivation of $A$. roxburghii grown under supplemental lighting with various light qualities (A: red light; B: blue light; C: yellow light; D: green light; E: white light; F: control) for $40 \mathrm{~d}$.

The age of $A$. roxburghii plants $(175 d)=120 d$ (in vitro $)+15 d$ (acclimation) $+40 d$ (supplemental lighting process). Photo credit: Wei Wang. 


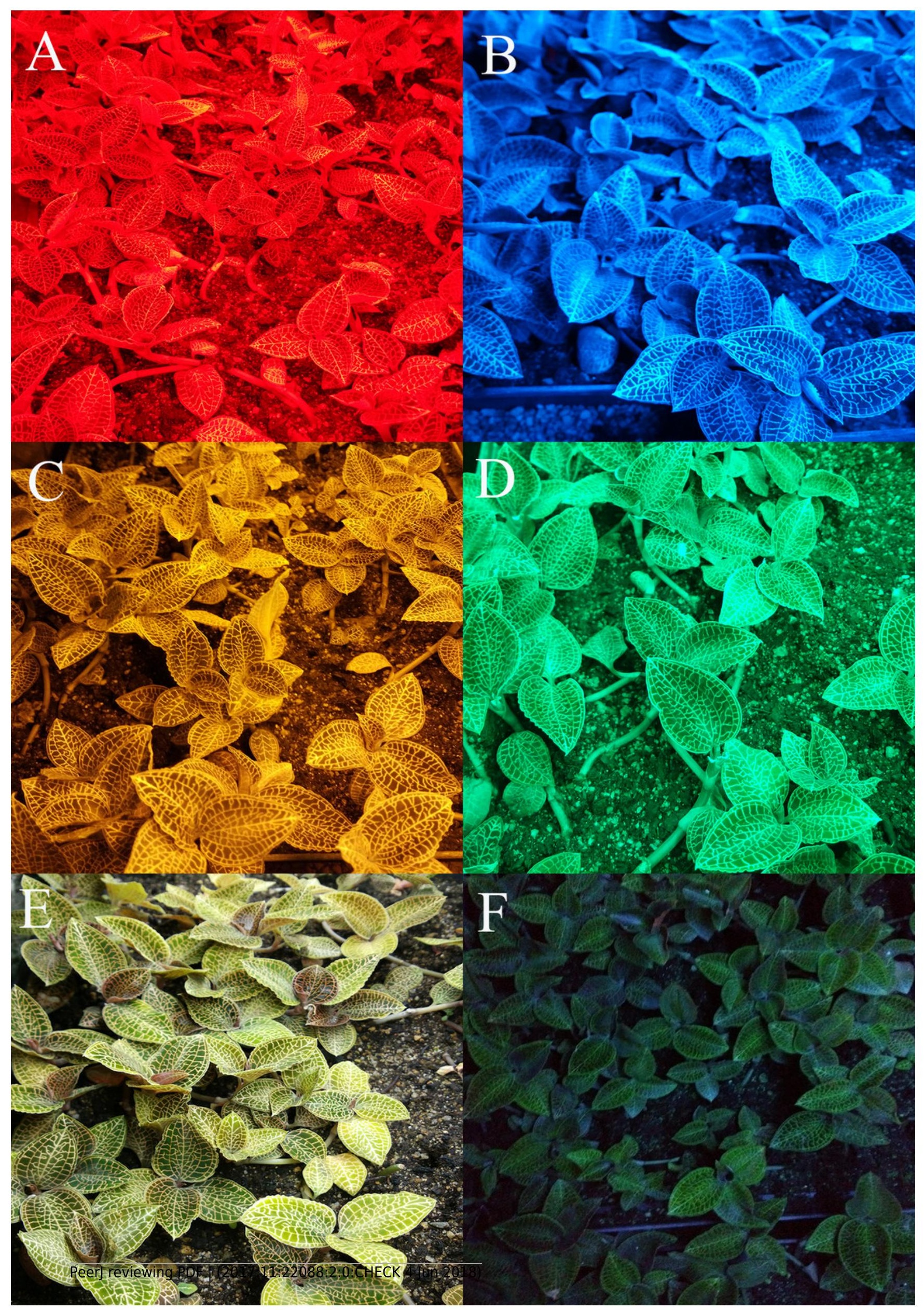


Figure 3

Appearance of $A$. roxburghii grown under supplemental lighting with different light qualities for $40 \mathrm{~d}$.

The age of $A$. roxburghii plants $(175 d)=120 d$ (in vitro $)+15 d$ (acclimation $)+40 d$ (supplemental lighting process). Photo credit: Wei Wang.

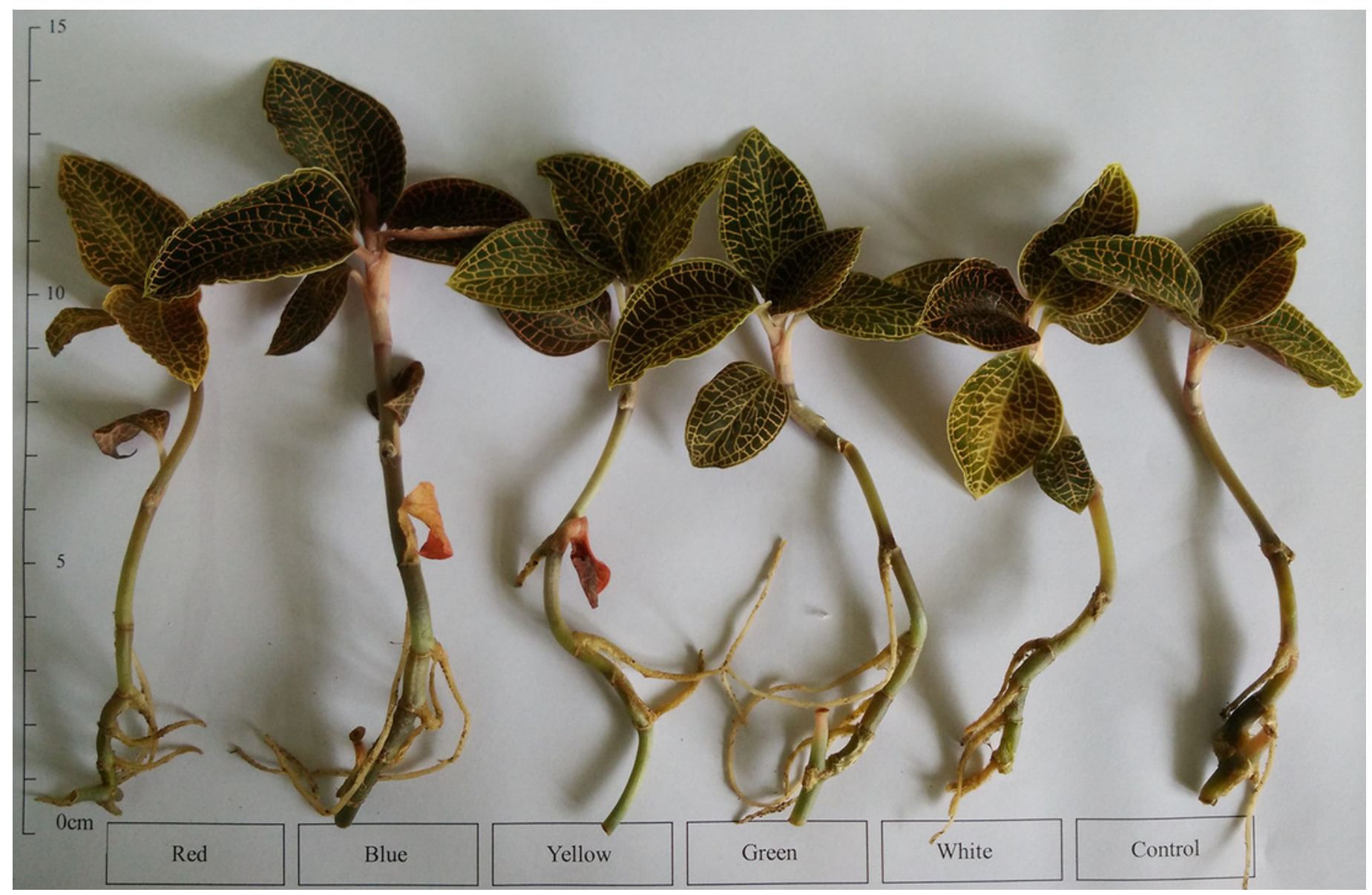


Figure 4(on next page)

Effects of supplemental lighting with different light qualities on chlorophyll content of $A$. roxburghii.

R: red light; B: blue light; Y: yellow light; G: green light; W: white light; CK: control. Values represent mean of three replicates, the bars represent the standard error. In the same row, values marked with different letters are significantly different $(P<0.05) . F$ and $P$ represent $F$-value and $P$-value of the ANOVA, respectively. 


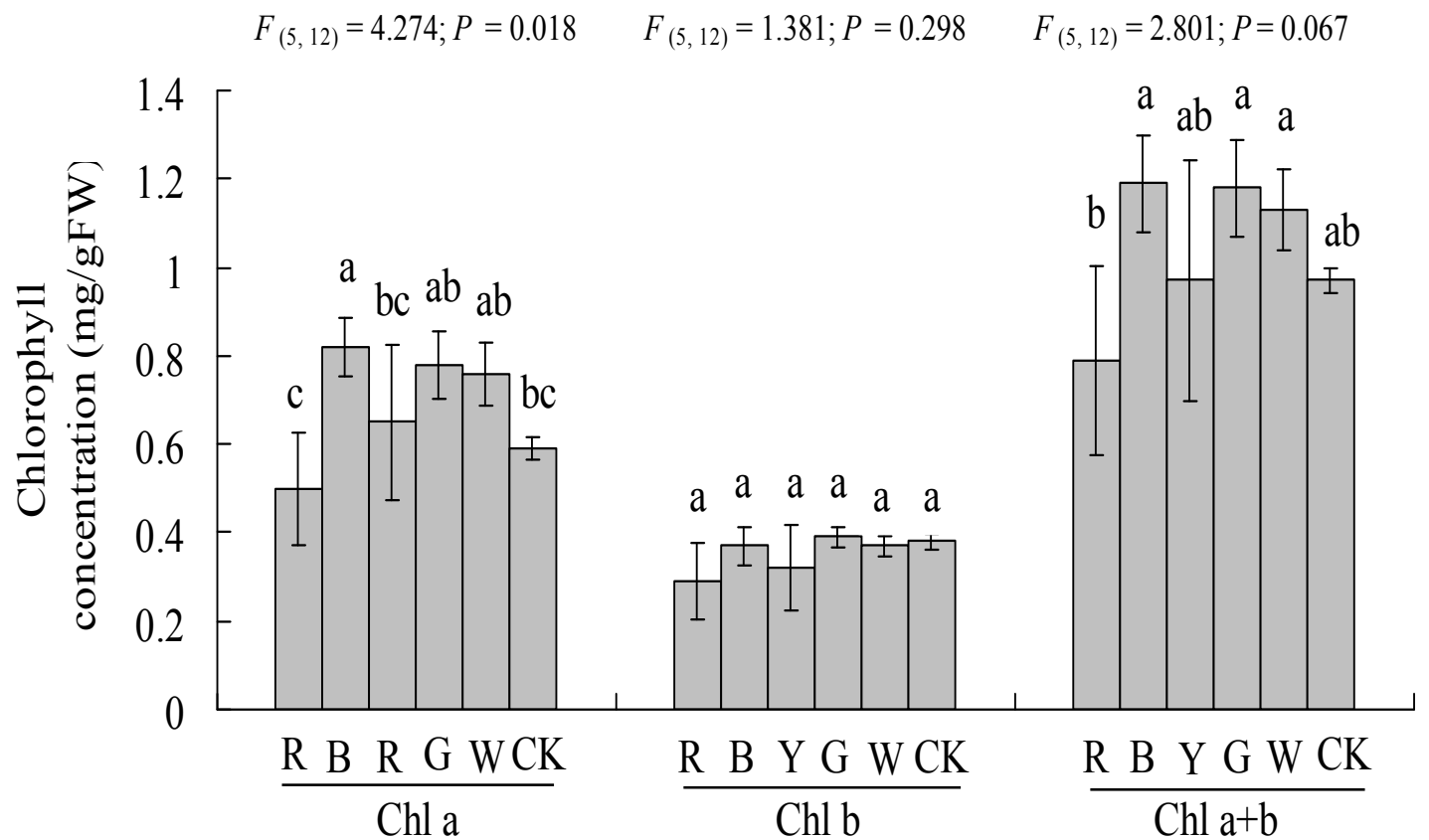


Figure $\mathbf{5}$ (on next page)

Effects of supplemental lighting with different light qualities on chlorophyll fluorescence of $A$. roxburghii.

R: red light; B: blue light; Y: yellow light; G: green light; W: white light; CK: control. Values represent mean of six replicates, the bars represent the standard error. In the same row, values marked with different letters are significantly different $(P<0.05)$. $F$ and $P$ represent $F$-value and $P$-value of the ANOVA, respectively. 


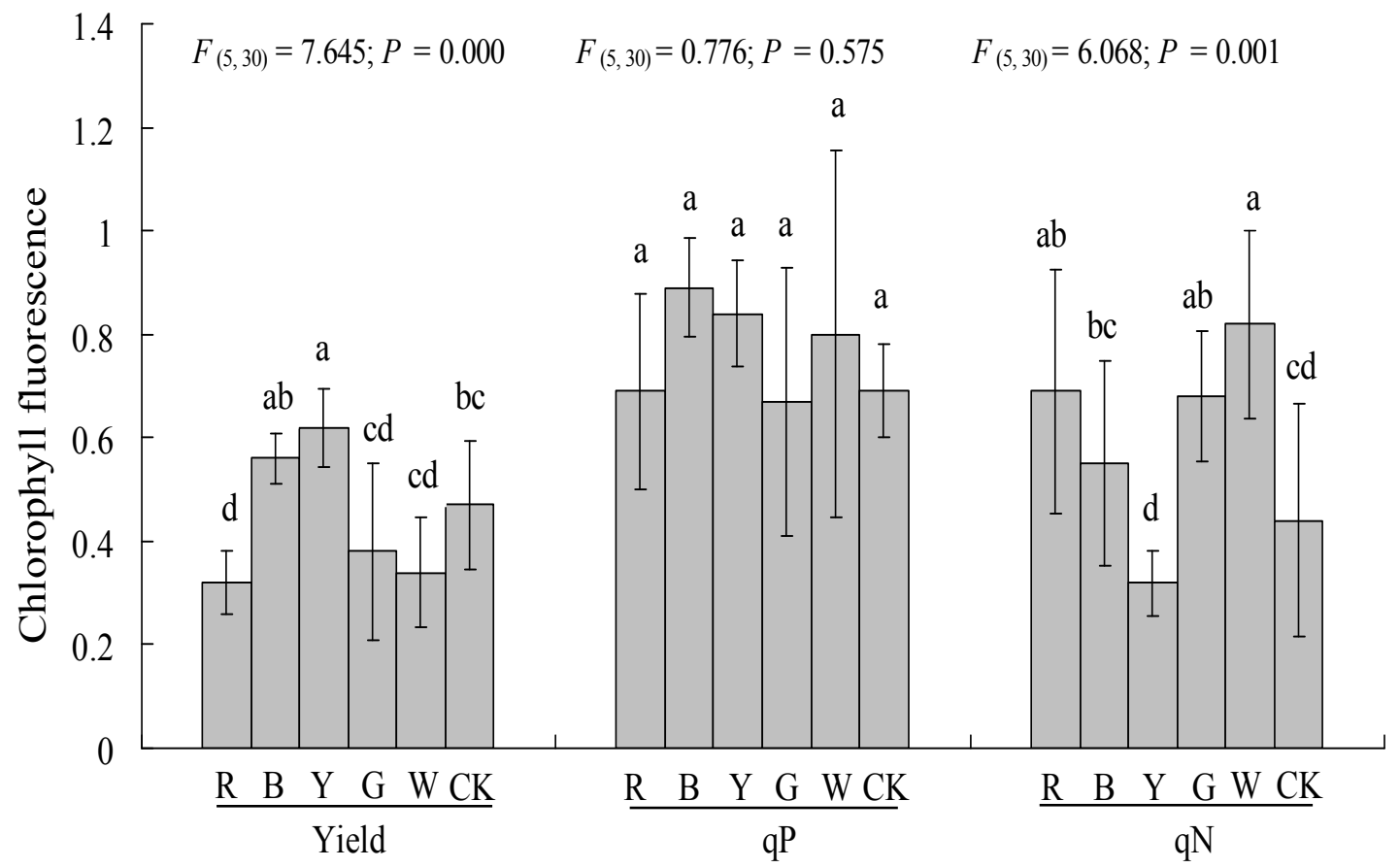


Figure 6 (on next page)

Effects of supplemental lighting with different light qualities on sugar content of $A$. roxburghii.

R: red light; B: blue light; Y: yellow light; G: green light; W: white light; CK: control. Values represent mean of three replicates, the bars represent the standard error. In the same row, values marked with different letters are significantly different $(P<0.05) . F$ and $P$ represent $F$-value and $P$-value of the ANOVA, respectively. 


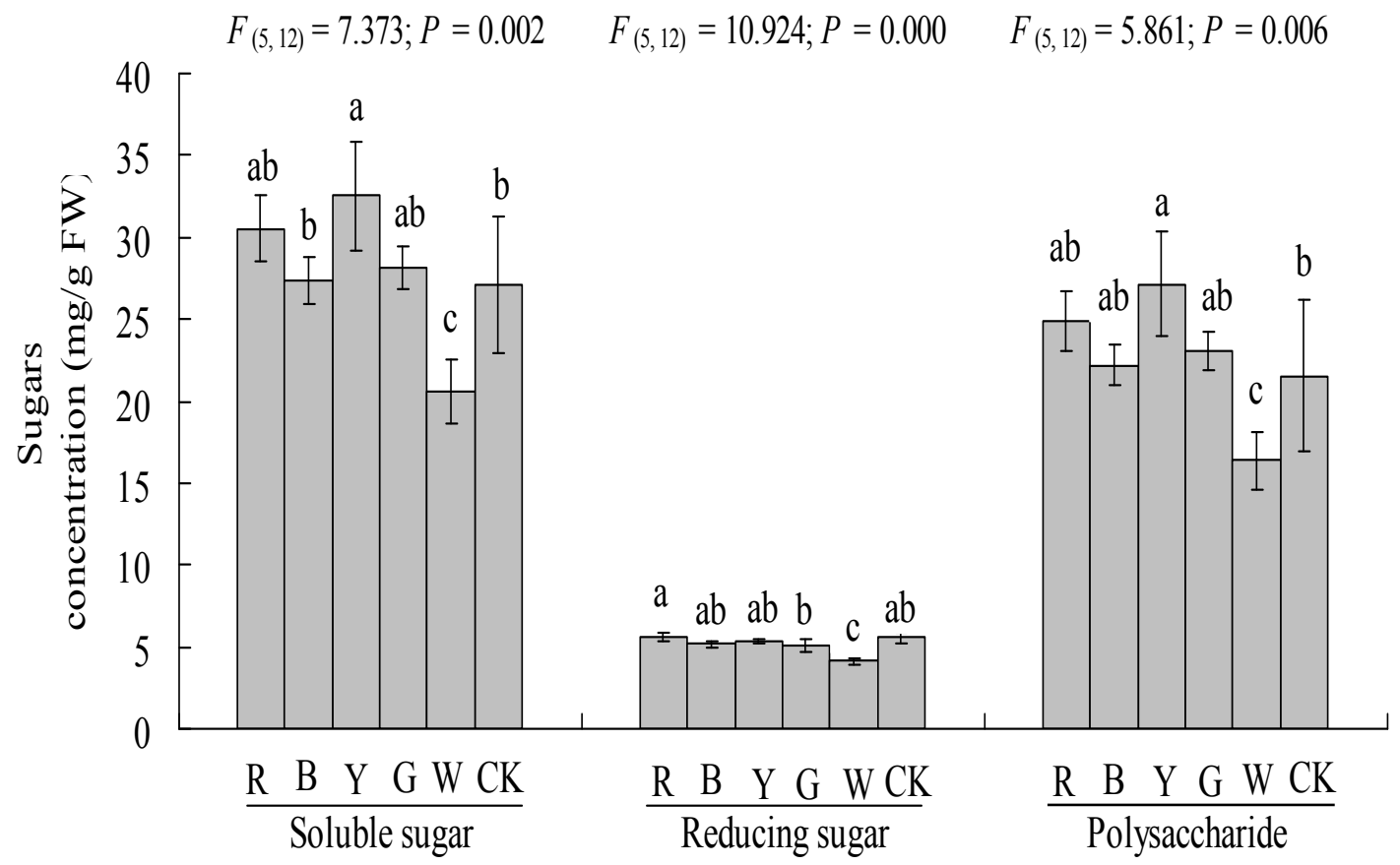




\section{Figure 7 (on next page)}

Effects of supplemental lighting with different light qualities on stomatal area (A), stomatal density (B), root vitality (C), soluble protein (D), total flavonoid content (E), total polyphenol content $(\mathrm{F})$ of $A$. roxburghii.

RL: red light; BL: blue light; YL: yellow light; GL: green light; WL: white light; CK: control. Values of stomatal area (A) and stomatal density (B) represent mean of ten replicates, values of root vitality $(C)$, soluble protein $(D)$, total flavonoid $(E)$ and total polyphenol $(F)$ represent mean of three replicates, the bars represent the standard error. In the same row, values with the same superscript letter are not significantly different $(P>0.05)$; those with different superscript letters are significantly different $(P<0.05) . F, P$ and $d f$ represent $F$-value, $P$-value and degree of freedom of the ANOVA, respectively. 

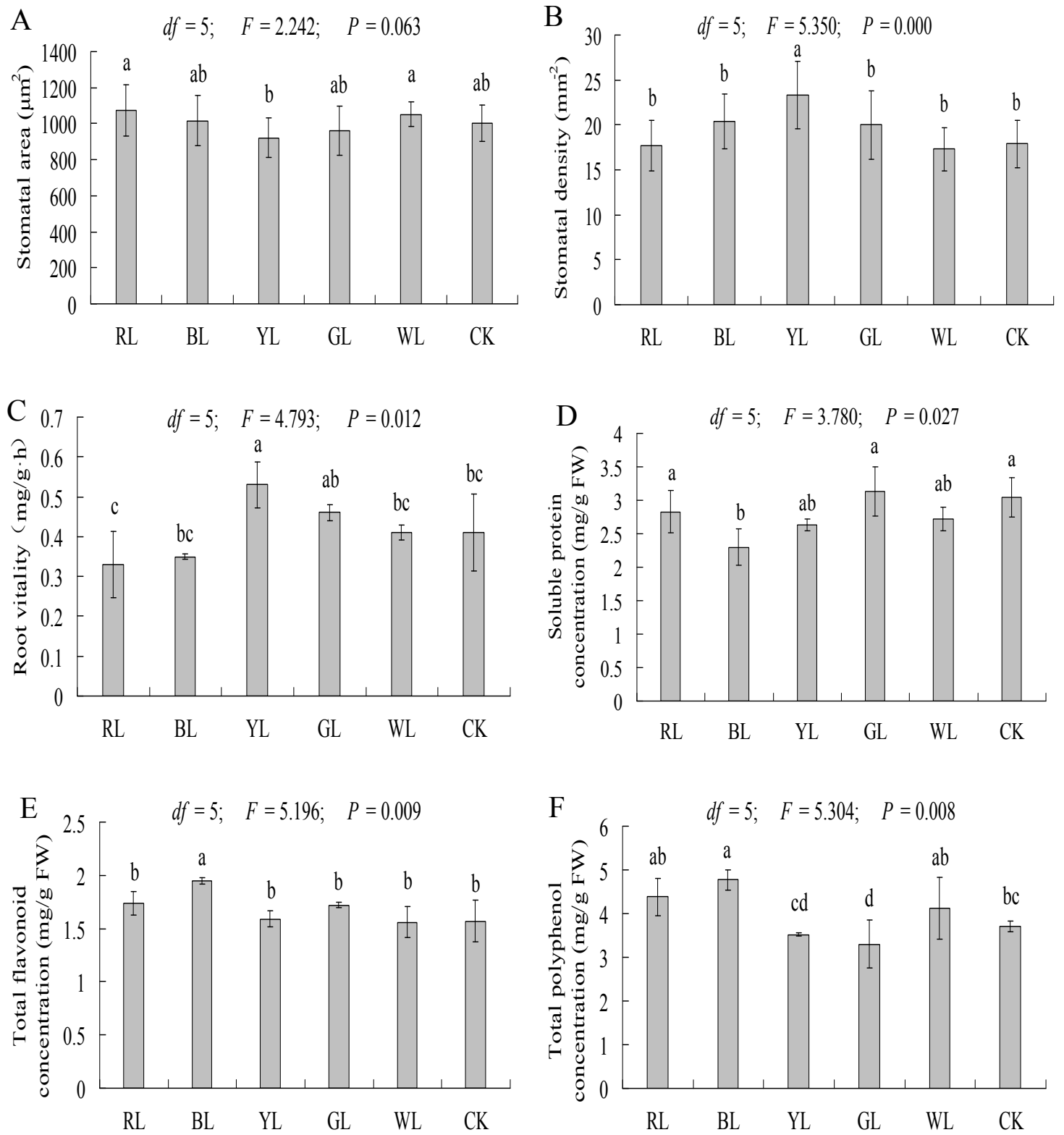